\title{
Adubação fosfatada e épocas de cultivo na composição química de sementes de cultivares de feijoeiro
}

\author{
Phosphorus fertilization and planting dates on the chemical seeds composition \\ of two dry bean cultivars
}

\author{
Claudemir Zucareli ${ }^{*}$ Raphael Rossi Silva ${ }^{I}$ Diego Gazola ${ }^{\mathrm{I}}$ \\ Danilo Pinceli Chaves ${ }^{I}$ João NakagawaII
}

\section{RESUMO}

$O$ fósforo $(P)$ é um nutriente limitante na produtividade do feijoeiro e pode influenciar na composição química de sementes. O trabalho objetivou avaliar os efeitos da adubação fosfatada e de épocas de cultivo ('águas' e 'seca'), na composição química de sementes de duas cultivares de feijoeiro. O experimento foi realizado em Botucatu (SP), no delineamento de blocos ao acaso com cinco repetições. As cultivares de feijão 'Carioca Precoce' e 'IAC Carioca Tybatã' foram avaliadas no cultivo 'das águas'e 'da seca' sob seis doses de $\mathrm{P}_{2} \mathrm{O}_{5}(0 ; 30 ; 60$; 90; 120 e $150 \mathrm{~kg} \mathrm{ha}^{-1}$ ) com aplicação de superfosfato triplo no sulco de semeadura. Amostras de sementes foram analisadas para determinação dos teores de $\mathrm{N}, \mathrm{P}, \mathrm{K}, \mathrm{Ca}, \mathrm{Mg}, \mathrm{S}, \mathrm{Cu}, \mathrm{Mn}, \mathrm{Fe}, \mathrm{Zn}$, açúcar total e redutor e proteína. A adubação fosfatada alterou a composição química das sementes, incremento nos teores de $P$ e redução de Ca e $\mathrm{Cu}$. Os teores de $\mathrm{K}$ e Fe apresentam ponto de mínima nas doses de 69,9 e 66 kg ha-1 de $\mathrm{P}_{2} \mathrm{O}_{5}$, respectivamente. $\mathrm{O}$ cultivo na época 'da seca' favorece os teores de $N$, $P$ e proteínas das sementes. A cultivar 'Carioca Precoce' apresenta maior teor de $N$ e proteínas nas sementes em relação a 'IAC Carioca Tybatã'. Há interação cultivar e época de cultivo para o teor de $S, \mathrm{Mn}, \mathrm{Fe}$, $\mathrm{Ca}, \mathrm{Mg}, \mathrm{Cu}$, açúcares totais e redutores.

Palavras-chave: Phaseolus vulgaris, macronutrientes, micronutrientes, qualidade de sementes.

\section{ABSTRACT}

Phosphorus is a limiting nutrient in common bean grain yield and may influence the chemical composition of seeds. The aim was to assess the effects of phosphorus fertilization and planting dates ('water'and 'dry') in the seeds chemical composition of two dry bean cultivars. A field experiment was carried out in Botucatu (SP) in a randomized block design with five replications. Two dry bean cultivars 'Carioca Precoce' e 'IAC Carioca Tybatã' were evaluated in growing 'water' and 'drought' in six levels of $\mathrm{P}_{2} \mathrm{O}_{5}\left(0,30,60,90,120\right.$ and $\left.150 \mathrm{~kg} \mathrm{ha}^{-1}\right)$ applying superphosphate at planting row. It was assessed seed samples to determine the levels of $\mathrm{N}, \mathrm{P}, \mathrm{K}, \mathrm{Ca}, \mathrm{Mg}, \mathrm{S}, \mathrm{Cu}, \mathrm{Mn}, \mathrm{Fe}, \mathrm{Zn}$, total and reducing sugar and protein. The phosphorus in the soil alters the seeds chemical composition, increasing contents of $\mathrm{P}$ and decreasing $\mathrm{Ca}$ and $\mathrm{Cu}$ contents. The $\mathrm{K}$ and $\mathrm{Fe}$ contents showed minimum point at a level of 69.9 and $66 \mathrm{~kg} \mathrm{ha}^{-1}$ of $\mathrm{P}_{2} \mathrm{O}_{5}$, respectively. It was observed that occurred increase in contents of $N, P$, and protein of seeds in the growing season 'drought'. The cultivar 'Carioca Precoce' showed higher $N$ content and protein of seeds than 'IAC Carioca Tybatã'. There is interaction between cultivar and growing season for the content of $\mathrm{S}, \mathrm{Mn}, \mathrm{Fe}, \mathrm{Ca}, \mathrm{Mg}, \mathrm{Cu}$, total and reducing sugars.

Key words: Phaseolus vulgaris, macronutrients, micronutrients, seed quality.

\section{INTRODUÇÃO}

O feijoeiro (Phaseolus vulgaris L.) é cultivado em diversas regiões brasileiras, em três épocas de semeadura (águas, seca e inverno), sob diferentes níveis tecnológicos, com produtividade de grãos média inferior a 1t ha-1 (SILVA et al., 2011). Dentre os fatores limitantes à elevada produtividade, tem-se a utilização de sementes de baixa qualidade (FARINELLI et al., 2006) e a baixa disponibilidade de fósforo (P) nos solos tropicais.

Feijoeirocultivadosobbaixa disponibilidade de $\mathrm{P}$ tem a expansão foliar comprometida, reduzindo o acúmulo de matéria seca, o crescimento, o desenvolvimento e o desempenho produtivo; além disso a deficiência de P limita a fixação biológica de $\mathrm{N}_{2}$, pois compromete a nodulação. Assim, o fornecimento

\footnotetext{
'Departamento de Agronomia, Centro de Ciências Agrárias, Universidade Estadual de Londrina (UEL), PR-445, km 380, 86051-990, Londrina, PR, Brasil. E-mail: claudemircca@uel.br. *Autor para correspondência.

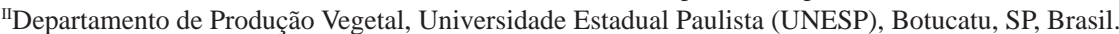


de P pode promover o crescimento inicial do feijoeiro e incrementar a produtividade e composição das sementes, particularmente sob condições de estresse ambiental (ARAÚJO et al., 2002).

A composição química da semente afeta diretamente a sua qualidade fisiológica, influenciando na germinação, no vigor e na armazenabilidade. Nesse aspecto, a adubação pode contribuir para a melhoria da composição química de sementes e a sua qualidade fisiológica. A adubação fosfatada pode incrementar os teores de nutrientes na semente, como, por exemplo, fósforo (P), magnésio (Mg) e zinco (Zn) (SALUM et al., 2008).

O efeito de genótipos, bem como a responsividade à adubação se constitui em fator determinante na composição química das sementes de feijão. A época das águas influenciou o teor proteico das cultivares 'Carioca' e 'CNFC 8005', com valores superiores a $20 \%$. A composição química pode ser afetada também pelo ambiente, assim as épocas de cultivo, em função dos contrastes climáticos, podem alterar a composição química da semente, bem como apresentar interações com o genótipo e a disponibilidade de $\mathrm{P}$ no solo. Por exemplo, o teor de proteínas é variável entre épocas de cultivo (FARINELLI \& LEMOS, 2010) e dependente das condições de ambiente (LAJOLO et al., 1996).

O trabalho objetivou avaliar os efeitos de doses de adubação fosfatada e de épocas de cultivo ('águas' e 'seca') sobre a composição química de sementes de duas cultivares de feijão.

\section{MATERIAL E MÉTODOS}

O experimento foi conduzido em Botucatu (SP), na latitude $22^{\circ} 45^{\prime}$ S e longitude $48^{\circ} 34^{\prime}$ W, com altitude de $750 \mathrm{~m}$. O clima, segundo Köppen é do tipo Cfa, ou seja, subtropical úmido com estiagem no período de inverno. O solo é classificado como Latossolo Vermelho distroférrico (SANTOS et al., 2006).

Os dados meteorológicos foram obtidos no Posto Meteorológico do Departamento de Recursos Naturais-Ciências Ambientais, pertencente à Faculdade de Ciências Agronômicas do Campus de Botucatu-UNESP, próximo ao local do experimento. A temperatura média variou entre 15 e $30^{\circ} \mathrm{C}$ (época 'das águas') e 15 e $25^{\circ} \mathrm{C}$ (época 'da seca'), a temperatura máxima variou entre 22 e $35^{\circ} \mathrm{C}$ (época 'das águas') e 18 e $30^{\circ} \mathrm{C}$ (época 'da seca'), a temperatura mínima variou entre 5 e $22^{\circ} \mathrm{C}$ (época 'das águas') e 7 e $20^{\circ} \mathrm{C}$ (época ‘da seca’). A precipitação pluvial acumulada foi de $428 \mathrm{~mm}$ (época ‘das águas’) e de 370mm (época ‘da seca’).
Utilizou-se o delineamento experimental de blocos ao acaso, com cinco repetições, em esquema fatorial $2 \times 2 \times 6$. As cultivares de feijoeiro 'Carioca Precoce' e 'IAC Carioca Tybatã' foram avaliadas em duas épocas ('águas’ e 'da seca’) sob seis doses de adubação fosfatada (0, 30, 60, 90, 120 e $150 \mathrm{~kg} \mathrm{ha}^{-1}$ de $\mathrm{P}_{2} \mathrm{O}_{5}$ ), tendo como fonte o superfosfato triplo aplicado no sulco de semeadura. Foi utilizado o sistema convencional de cultivo (uma aração e duas gradagens), com calagem dois meses antes da semeadura.

O solo foi analisado na camada $0-20 \mathrm{~cm}$, de acordo com a metodologia de RAIJ et al. (2001): a) época ‘das águas' - pH (4,9 - $\left.\mathrm{CaCl}_{2}\right)$, M.O. (26g dm³), P trocável (6,75mg dm $\left.{ }^{-3}\right), \mathrm{H}+\mathrm{Al}\left(41,8 \mathrm{mmol}_{\mathrm{c}} \mathrm{dm}^{-3}\right), \mathrm{K}$ trocável $\left(6,4 \mathrm{mmol}_{\mathrm{c}} \mathrm{dm}^{-3}\right)$, Ca trocável $\left(21,8 \mathrm{mmol}_{\mathrm{c}} \mathrm{dm}^{-3}\right)$, Mg trocável (14, 3mmol $\left.\mathrm{dm}^{-3}\right)$, SB $\left(42,5 \mathrm{mmol}_{\mathrm{c}} \mathrm{dm}^{-3}\right)$, CTC (84,3mmol dm $\left.{ }^{-3}\right), \mathrm{V}(48,8 \%), \mathrm{Cu}\left(7,8 \mathrm{mg} \mathrm{dm}^{-3}\right)$, Fe (19,8mg dm $\left.{ }^{-3}\right)$, Mn (55,4mg dm $\left.{ }^{-3}\right)$ e Zn (2,1mg $\left.\mathrm{dm}^{-3}\right)$; b) época 'da seca' - pH (4,5 - $\left.\mathrm{CaCl}_{2}\right)$, M.O. (24g $\left.\mathrm{dm}^{-3}\right)$, P trocável $\left(4 \mathrm{mg} \mathrm{dm} \mathrm{dm}^{-3}\right), \mathrm{H}+\mathrm{Al}\left(34 \mathrm{mmol}_{\mathrm{c}} \mathrm{dm}^{-3}\right)$, K trocável $\left(4,5 \mathrm{mmol}_{\mathrm{c}} \mathrm{dm}^{-3}\right)$, Ca trocável $\left(20 \mathrm{mmol}_{c}\right.$ $\left.\mathrm{dm}^{-3}\right)$, Mg trocável $\left(6 \mathrm{mmol} \mathrm{dm}^{-3}\right)$, SB $\left(30 \mathrm{mmol} \mathrm{dm}^{-3}\right)$, CTC (64mmol dm $\left.{ }^{-3}\right), \mathrm{V}(47 \%), \mathrm{Cu}\left(10,2 \mathrm{mg} \mathrm{dm}^{-3}\right), \mathrm{Fe}$ (15mg dm $\left.\mathrm{m}^{-3}\right)$, Mn (42,3mg dm $\mathrm{m}^{-3}$ ) e $\mathrm{Zn}\left(1,7 \mathrm{mg} \mathrm{dm}^{-3}\right)$.

As parcelas apresentaram seis linhas de $10 \mathrm{~m}$ de comprimento, espaçadas $0,5 \mathrm{~m}$ entre si. A área útil consistiu das quatro linhas centrais, desprezandose $0,5 \mathrm{~m}$ em cada extremidade, totalizando $18 \mathrm{~m}^{2}$. Foram aplicados $10 \mathrm{~kg} \mathrm{ha}^{-1}$ de $\mathrm{K}_{2} \mathrm{O}$ na forma de cloreto de potássio e $10 \mathrm{~kg} \mathrm{ha}^{-1}$ de $\mathrm{N}$ na forma de ureia, no momento da semeadura, de acordo com análise química do solo. Em cobertura, foram aplicados $60 \mathrm{~kg}$ $\mathrm{ha}^{-1}$ de $\mathrm{N}$, na forma de ureia, parcelados aos 15 e 30 dias após a emergência. A densidade de semeadura foi de 240.000pl ha-1.

Amostras de sementes retidas em peneira de crivo oblongo 11/64"x3/4, foram secas em estufa de ventilação forçada a $65^{\circ} \mathrm{C}$, moídas e analisadas para determinação de nitrogênio $(\mathrm{N})$, fósforo $(\mathrm{P})$, potássio $(\mathrm{K})$, cálcio $(\mathrm{Ca})$, magnésio $(\mathrm{Mg})$, enxofre (S), cobre $(\mathrm{Cu})$, manganês $(\mathrm{Mn})$, ferro $(\mathrm{Fe})$ e zinco (Zn) (MALAVOLTA et al., 1989). O teor de proteína das sementes foi obtido multiplicando-se o teor de $\mathrm{N}$ pelo índice 6,25. Os teores de açúcares total (AT) e açúcares redutor (AR) foram determinados pelo método de DUBOIS et al. (1956) e NELSON (1944), respectivamente.

Para a análise dos dados coletados, foi procedida, inicialmente, a verificação das pressuposições do modelo matemático. Em seguida, procedeu-se à análise de variância, teste Tukey e regressão até segundo grau, a 5\% de significância. 


\section{RESULTADOS E DISCUSSÃO}

Os teores de $\mathrm{N}$ e proteína foram influenciados pelas épocas de cultivo e pelas cultivares. Contudo, não ocorreu efeito da adubação fosfatada no teor do $\mathrm{N}$. Maiores teores de $\mathrm{N}$ na semente foram observados na época de cultivo 'da seca', enquanto que, na comparação entre cultivares, a 'Carioca Precoce' foi superior à cultivar 'IAC Carioca Tybatã’ (Tabela 1).

O teor de proteínas foi maior na época 'da seca' (25,2\%), assim como a cultivar 'Carioca Precoce’ apresentou o maior teor nas duas épocas de cultivo (24,5\%). O teor de proteína na época 'das águas’ foi de $21,2 \%$, sendo um resultado semelhante ao obtido para outras cultivares (29 cultivares) na época 'das águas' (LEMOS et al., 2004). A variação no teor de proteína entre épocas também foi relatada por FARINELLI E LEMOS (2010), que observaram maior teor proteico na época 'da seca'. Segundo
LAJOLO et al. (1996), a variação no teor de proteínas está diretamente relacionada à genética e às condições climáticas (temperatura e precipitação pluvial). O efeito de temperatura elevada pode explicar a menor concentração de proteínas na época das 'águas', porque o estresse térmico pode ocasionar efeitos fisiológicos que acarretaram distúrbios bioquímicos na biossíntese de proteínas (BURATTO et al., 2009).

O teor proteico geralmente está associado a sementes de melhor qualidade fisiológica, o que favorece o desenvolvimento inicial das plântulas, principalmente sob condições desfavoráveis (HENNING et al., 2010). Entretanto, a produção de sementes de elevado teor proteico pode estar associada à menor produtividade de sementes ( $\mathrm{kg} \mathrm{ha}^{-1}$ ) (LEMOS et al., 2004). Essa situação deve-se à complexidade do controle genético para o teor de proteínas que depende de genes que controlam a síntese, acúmulo de proteínas, absorção de nutrientes, vigor da planta e tamanho de grãos (REYES-MORENO; PAREDE-LÓPEZ, 1993).

Tabela 1 - Teores de macro e micronutrientes (N, P, K, Ca, Zn, S, Mn, Fe, Mg e Cu), proteínas e açúcares de sementes de duas cultivares de feijão, em duas épocas de cultivo.

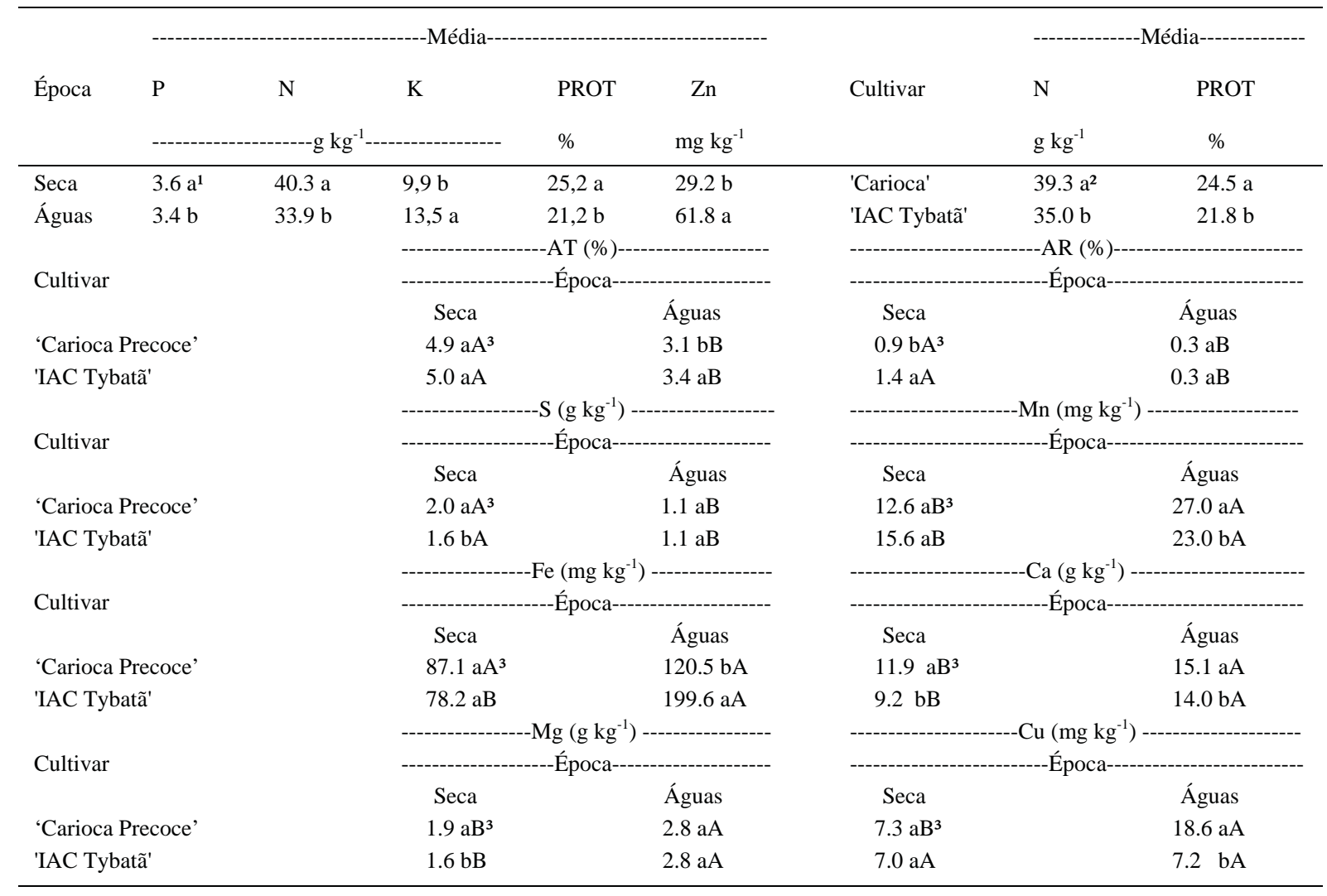

( $\left.{ }^{1}\right)$ Compara o efeito de épocas. $\left({ }^{2}\right)$ Compara o efeito de cultivares. $\left({ }^{3}\right)$ Letras minúsculas na coluna comparam efeito de cultivares e maiúsculas na linha, efeito de épocas.

Médias seguidas de mesma letra não diferem entre si pelo Teste Tukey em nível de 5\%. 
Em média, o cultivo da seca incrementou o teor de $\mathrm{P}$ na semente (Tabela 1), possivelmente, por causa da diluição do $\mathrm{P}$ em decorrência da menor produtividade em condições de menor disponibilidade hídrica, na fase reprodutiva da cultura. Além disso, ocorreu resposta quadrática para o teor de $\mathrm{P}$ com o aumento da dose de fósforo aplicado no solo (Figura 1). A maior disponibilidade de $\mathrm{P}$ pode afetar positivamente a composição química e consequentemente a qualidade fisiológica das sementes (GUERRA et al., 2006); contudo, a resposta depende da genética e do ambiente (ZUCARELI et al., 2011), o que corrobora os resultados obtidos neste trabalho.

O aumento do teor de $\mathrm{P}$ na semente via adubação no sulco de semeadura, é um resultado importante. A implantação da cultura com sementes de maior teor desse nutriente favorece a nodulação

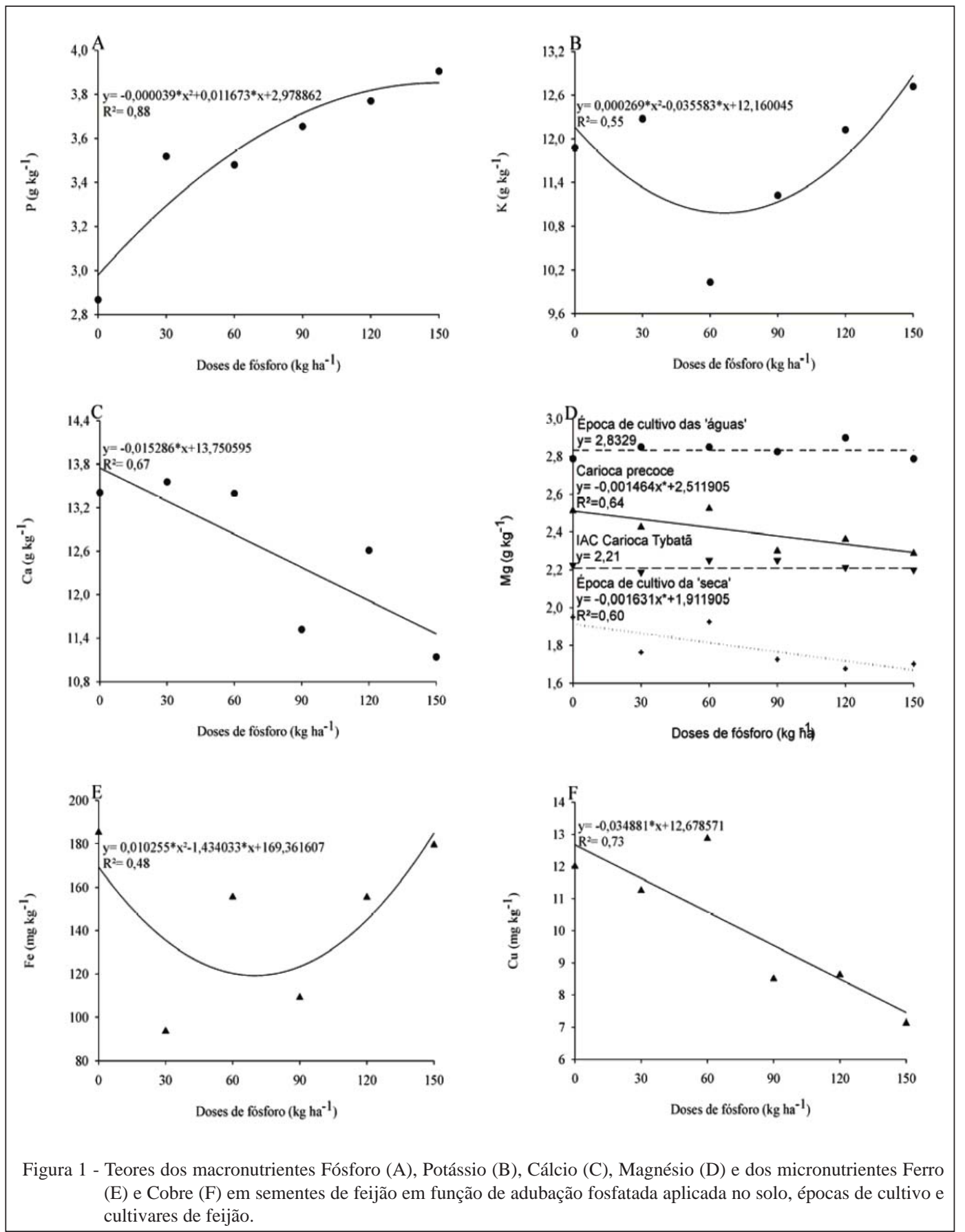

Ciência Rural, v.44, n.9, set, 2014. 
e o acúmulo de $\mathrm{N}$ em plantas de feijoeiro no estádio vegetativo, particularmente quando utilizadas em semeaduras com baixas doses de P aplicadas via solo (ARAÚJO et al., 2002). Plantas de feijão originadas de sementes com elevado teor de P apresentam maior crescimento vegetativo e são menos dependentes do suprimento desse mineral do solo para produção de biomassa (ARAUJO et al., 2002). Entretanto, SILVA et al. (2003) afirmaram que os efeitos do teor de P na semente no desempenho da planta dependem da condições de fertilidade do solo, temperatura e precipitação pluvial, com resultados mais evidentes em solo deficiente de P.

A interação cultivar e época de cultivo foi significativa para os teores de S, Mn, AT e AR (Tabela 1). O teor de $S$ foi superior para a cultivar 'Carioca Precoce' cultivada na época 'da seca', apresentando semelhança com os resultados de teor proteico quanto ao comportamento na resposta. MESQUITA et al. (2007) também observaram maiores teores de $\mathrm{S}$ em grãos com elevado teor proteico. A relação entre $S$ e teor proteico deve-se ao fato do $S$ participar ativamente na formação das proteínas (WIESER et al., 2004).

Foram observados maiores teores de AT e AR na época 'da seca' para ambas cultivares (Tabela 1), sem efeito da adubação fosfatada para ambas as características. O maior teor de açúcares nas sementes pode ser vantajoso, devido ao fornecimento de energia para as sementes, o que resulta em sementes mais vigorosas (HENNING et al., 2010) e, consequentemente, em maior porcentagem de emergência de plântulas no campo.

O teor de Mg na semente não foi influenciado pela adubação fosfatada na época das ‘águas’ (Figura 1). Contudo, no cultivo da 'seca', o teor de Mg diminuiu com o incremento da adubação fosfatada. $\mathrm{O}$ teor de $\mathrm{Mg}$ não variou com a adubação de P para a cultivar 'IAC Carioca Tybatã’; resposta semelhante para essa cultivar foi relatada por SALUM et al. (2008). Entretanto, o aumento da adubação com fósforo ocasionou a redução no teor de Mg na cultivar 'Carioca Precoce'. SALUM et al. (2008), constataram um aumento no teor de $\mathrm{Mg}$ na semente em função ao aumento da adubação com fósforo. O maior teor de Mg foi observado na época das ‘águas' para ambas as cultivares (Figura 1). O menor teor do nutriente ocorreu para a cultivar 'IAC Carioca Tybatã' na época 'da seca’, independentemente da adubação fosfatada. A disponibilidade de Mg na semente é determinante no desenvolvimento inicial da plântula, porque interfere na transferência de energia da célula, na respiração e na fotossíntese, e na produção de matéria seca da parte aérea (SOUZA JÚNIOR et al., 1998).
O teor de Mn foi influenciado pela interação época de cultivo e cultivares, em que para ambas o maior teor de Mn foi observado na época das 'águas' (Tabela 1). A cultivar 'Carioca Precoce' apresentou maior teor do nutriente na época das 'águas’ e não diferiu da IAC Tybatã na época da 'seca’. O maior teor de Mn nas sementes é fundamental para garantir nutrição adequada das plântulas e prevenir deficiência inicial no campo (MANN et al., 2001).

$\mathrm{O}$ maior teor de $\mathrm{Ca}$ na semente foi observado na época das ‘águas', sendo que a cultivar 'Carioca Precoce' apresentou maior teor de Ca nas duas épocas de cultivo (Tabela 1). Os teores de Ca e $\mathrm{Cu}$ na semente decresceram com o aumento da dose de P (Figura 1). Essa diferença no teor de Ca nas sementes entre cultivares corrobora o estudos nos quais foi observado que há diferenças no teor de Ca entre cultivares de feijão (MIGLIORANZA et al., 2003; JOST et al., 2008). A maior disponibilidade de Ca nas sementes pode contribuir na melhoria da qualidade fisiológica de sementes de feijão, devido ao aumento da resistência do tegumento a danos mecânicos (BEVILAQUA et al., 2002).

$\mathrm{O}$ teor de $\mathrm{Fe}$ nas sementes da cultivar ‘Carioca Precoce’ não diferiu entre as épocas de cultivo; por outro lado, a cultivar 'IAC Carioca Tybatã' apresentou valores superiores à 'Carioca Precoce’ na época ‘das águas’ (Tabela 1). As cultivares de feijão respondem diferentemente às alterações ambientais, principalmente de temperatura e umidade (ZIMMERMAM et al., 1996), justificando as variações na composição química relatada anteriormente entre cultivares dentro das épocas de cultivo.

$\mathrm{O}$ teores de $\mathrm{Fe}$ e $\mathrm{K}$ apresentaram ajuste quadrático às doses de $\mathrm{P}$ no solo, sendo os menores valores nas doses de 69,9 e 66 kg ha-1 de $\mathrm{P}_{2} \mathrm{O}_{5}$, respectivamente (Figura 1 ). Tais resultados contrastam com os relatados por SALUM et al. (2008), que não observaram efeito da dose de fósforo no teor de Fe. Os teores de $\mathrm{K}$ e $\mathrm{Zn}$ nas sementes foram superiores na época 'das águas' (Tabela 1). Esses resultados podem estar associados ao melhor aproveitamento da adubação ou dos nutrientes do solo pela planta em condições climáticas favoráveis, principalmente disponibilidade hídrica, como ocorrido na fase reprodutiva do feijão cultivado na época das águas.

$\mathrm{O}$ aumento do teor de minerais em grãos é benéfico tanto para a nutrição humana, quanto para o sistema de produção agrícola. Além disso, o maior teor de nutrientes nas sementes pode indicar melhor qualidade, e originar plântulas mais vigorosas e resistentes à doenças e mais eficientes no uso da água (FROSSARD et al., 2000). 


\section{CONCLUSÃO}

A adubação fosfatada no solo eleva os teores de $\mathrm{P}$ e reduz os teores de $\mathrm{Ca}$ e $\mathrm{Cu}$ das sementes. Os teores de $\mathrm{K}$ e $\mathrm{Fe}$ em sementes de feijoeiro decrescem com doses de até 69,9 e 66kg ha-1 de $\mathrm{P}_{2} \mathrm{O}_{5}$, respectivamente. $\mathrm{O}$ incremento nas doses de $\mathrm{P}$ no cultivo da 'seca' reduz o teor de Mg das sementes para a cultivar 'Carioca Precoce'. O cultivo na época 'da seca' incrementa os teores de N, P e proteínas das sementes. A cultivar 'Carioca Precoce' apresenta sementes de maior teor de $\mathrm{N}$ e proteínas em relação à 'IAC Carioca Tybatã'. Os teores de S, Mn, Fe, Ca, $\mathrm{Mg}, \mathrm{Cu}$, açúcares totais e redutores dependem da interação cultivar e época de cultivo.

\section{REFERÊNCIAS}

ARAÚJO, A.P. et. al. Efeitos do aumento do teor de fósforo na semente, obtido via adubação foliar, no crescimento e na nodulação do feijoeiro. Revista Brasileira de Ciência do Solo, v.26, n.1, p.183-189, 2002. Disponível em: <http://sbcs.solos.ufv.br/solos/ revistas/v26n1a19.pdf>. Acesso em: 20 nov. 2012.

BEVILAQUA, G.A.P. et al. Aplicação foliar de cálcio e boro e componentes de rendimento e qualidade de sementes de soja. Ciência Rural, v.32, p.31-34, 2002. Disponível em: <http://www. scielo.br/pdf/cr/v32n1/a06v32n1.pdf>. Acesso em: 20 nov. 2012. doi: 10.1590/S0103-84782002000100006.

BURATTO, J.S. et al. Variabilidade genética e efeito do ambiente para o teor de proteína em grãos de feijão. Acta Scientiarum Agronomy, v.31, n.4, p.593-597, 2009. Disponível em: <http:// periodicos.uem.br/ojs/index.php/ActaSciAgron/article/ view/910/910>. Acesso em: 20 nov. 2012. doi: 10.4025/ actasciagron.v31i4.910.

DUBOIS, M. et al. Colorimetric method for determination of sugars and related substances. Analytical Chemistry, v.28, n.3, p.350358, 1956. Disponível em: <http://pubs.acs.org/doi/pdf/10.1021/ ac60111a017>. Acesso em: 20 nov. 2012. doi: 10.1021/ac60111a017.

FARINELLI, R. et al. Produtividade e qualidade fisiológica de sementes de feijão em função de sistemas de manejo de solo e adubação nitrogenada. Revista Brasileira de sementes, v.28, n.2, p.102-109, 2006. Disponível em: <http://www.scielo.br/pdf/rbs/ v28n2/a13v28n2.pdf>. Acesso em: 20 nov. 2012. doi: 10.1590/ S0101-31222006000200013.

FARINELLI, R.; LEMOS, L.B. Qualidade nutricional e tecnológica de genótipos de feijão cultivados em diferentes épocas agrícolas. Bragantia, v.69, n.3, p.759-764, 2010. Disponível em: $<$ http://www.scielo.br/pdf/brag/v69n3/30.pdf $>$. Acesso em: 20 nov. 2012. doi: 10.1590/S0006-87052010000300030.

FROSSARD, E. et al. Potential for increasing the content and bioavailability of $\mathrm{Fe}, \mathrm{Zn}$ and $\mathrm{Ca}$ in plants for human nutrition. Journal of the Science of Food and Agriculture, v.80, n.7, p.861-879, 2000. Disponível em: <http://onlinelibrary.wiley.com/ doi/10.1002/(SICI)1097-0010(20000515)80:7\%3C861::AIDJSFA601\%3E3.0.CO;2-P/pdf>. Acesso em: 20 nov. 2012. doi: 10.1002/ (SICI)1097-0010(20000515)80:7<861::AID-JSFA601>3.0.CO;2-P.
GUERRA, C.A. et al. Qualidade fisiológica de sementes de soja em função da adubação com fosforo, molibdênio e cobalto. Acta Scientiarum Agronomy, v.28, n.1, p.91-97, 2006. Disponível em: <http://periodicos.uem.br/ojs/index.php/ActaSciAgron/ article/view/1678/1043>. Acesso em: 20 nov. 2012. doi: 10.4025/ actasciagron.v28i1.1678.

HENNING, F.A. et al. Composição química e mobilização de reservas em sementes de soja de alto e baixo vigor. Bragantia, v.69, n.3, p.727-734, 2010. Disponível em: <http://www.scielo.br/ pdf/brag/v69n3/26.pdf >. Acesso em: 20 nov. 2012. doi: 10.1590/ S0006-87052010000300026.

JOST, E. et al. Efeitos gênicos do teor de cálcio em grãos de feijão. Ciência Rural, v.39, n.1, p.31-37, 2008. Disponível em: <http:// www.scielo.br/pdf/cr/v39n1/a55cr689.pdf>. Acesso em: 20 nov. 2012. doi: 10.1590/S0103-84782008005000055.

LAJOLO, F.M. et al. Qualidade nutricional. In: ARAUJO, R.S. et al. (Coord.). Cultura do feijoeiro comum no Brasil. Piracicaba: Potafós, 1996. p.23-56.

LEMOS, L.B. et al. Características agronômicas e tecnológicas de genótipos de feijão do grupo comercial Carioca. Pesquisa Agropecuária Brasileira, v.39, n.4, p.319-326, 2004. Disponível em: <www.scielo.br/pdf/pab/v39n4/20440.pdf>. Acesso em: 20 nov. 2012. doi: 10.1590/S0100-204X2004000400004.

MALAVOLTA, E.; VITTI, G.C.; OLIVEIRA, A.S. Avaliação do estado nutricional das plantas: princípios e aplicações. Piracicaba: Associação Brasileira para Pesquisa da Potassa e do Fosfato. 1989. 201p.

MANN, E.N. et al. Efeito da adubação com manganês, via solo e foliar em diferentes épocas na cultura da soja (Glycine max (L.) Merril). Ciência e Agrotecnologia, v.25, n.2, p.264-273, 2001. Disponível em: <http://www.editora.ufla.br/_adm/upload/ revista/25-2-2001_04.pdf>. Acesso em: 20 nov. 2012.

MESQUITA, F.R. et al. Linhagens de feijão (Phaseolus vulgaris L.): Composição química e digestibilidade protéica. Ciência e Agrotecnologia, v.31, n.4, p.1114-1121, 2007. Disponível em: $<$ www.scielo.br/pdf/cagro/v31n4/26.pdf>. Acesso em: 20 nov. 2012. doi: 10.1590/S1413-70542007000400026.

MIGLIORANZA, E. et al. Teor de cálcio em frutos de diferentes cultivares de feijão-vagem. Horticultura Brasileira, v.21, n.2, p.158-161, 2003. Disponível em: <http://www.scielo.br/pdf/hb/ v21n2/a07v21n2.pdf>. Acesso em: 20 nov. 2012. doi: 10.1590/ S0102-05362003000200007.

NELSON, N. A photometric adaptation of the somogyi method for the determination of glucose. Journal of Chemical Biology, v.153, p.375-380, 1944. Disponível em: <http://xa.yimg.com/kq/ groups/22975017/567938699/name/375.full.pdf>. Acesso em: 20 nov. 2012.

RAIJ, B.V. et al. Análise química para avaliação da fertilidade de solos tropicais. Campinas: Instituto Agronômico, 2001. 285p.

REYES-MORENO, C.; PAREDE-LÓPEZ, O. Hard-to-Cook Phenomenon in common bean: a review. Critical Reviews Food Science Nutrition, v.33, n.3, p.227-286, 1993.

SALUM, J.D. et al. Características químicas e fisiológicas de sementes de feijão em função do teor de fosforo na semente e doses 
de fosforo no solo. Revista Brasileira de Sementes, v.30, n.1, p.140-149, 2008. Disponível em: <http://www.scielo.br/pdf/rbs/ v30n1/a18v30n1.pdf>. Acesso em: 20 nov. 2012. doi: 10.1590/ S0101-31222008000100018.

SANTOS, H.G. dos et al. Sistema brasileiro de classificação de solos. 2.ed. Rio de Janeiro: Embrapa Solos, 2006. 306p.

SILVA, R.J.S. et al. Rendimento de grãos no feijoeiro em função dos teores de fósforo nas sementes. Revista Brasileira de Agrociência, v.9, n.3, p.247-250, 2003. Disponível em: <http:// www.ufpel.tche.br/faem/agrociencia/v9n3/artigo11.pdf>. Acesso em: 20 nov. 2012.

SILVA, T.R.B. et al. Produtividade e características tecnológicas de cultivares de feijão em resposta à calagem superficial em plantio direto. Bragantia, v.70, n.1, p.196-205, 2011. Disponível em: <www.scielo.br/pdf/brag/v70n1/v70n1a26.pdf>. Acesso em: 20 nov. 2012. doi: 10.1590/S0006-87052011000100026.

SOUZA JÚNIOR, J.O. et al. Resposta do feijoeiro cultivado em solução nutritiva a níveis de cálcio e magnésio na presença de alumínio. Pesquisa Agropecuária Brasileira, v.33, n.7, p.1143-1148, 1998. Disponível em: <http://seer.sct.embrapa. br/index.php/pab/article/view/4941/7073>. Acesso em: 09 dez. 2013.

WIESER, $\mathrm{H}$. et al. Influence of sulphur fertilization on quantities and proportions of gluten protein types in wheat flour. Journal of Cereal Science, v.40, n.3, p.239-244, 2004. Disponível em: <http://www.sciencedirect.com/science/article/ pii/S0733521004000748>. Acesso em: 20 nov. 2012. doi: 10.1016/j.jcs.2004.05.005.

ZIMMERMAM, M.J.O. et al. Melhoramento genético e cultivares. In: ARAÚJO, R.S. et al. Cultura do feijoeiro comum no Brasil. Piracicaba: POTAFÓS, 1996. p.223-273.

ZUCARELI, C. et al. Fósforo na produtividade e qualidade de sementes de feijão Carioca Precoce cultivado no período das águas. Revista Ciência Agronômica, v.42, n.1, p.32-38, 2011. Disponível em: <http://www.ccarevista.ufc.br/seer/ index.php/ccarevista/article/viewFile/749/506>. Acesso em: 20 nov. 2012. 